\title{
Pregnancy-specific reference intervals for C-reactive protein improve diagnostic accuracy for infection: a cross-sectional and diagnostic accuracy study
}

\author{
Samuel Dockree ${ }^{1}$, Jennifer Brook ${ }^{1}$, Tim James ${ }^{1}$, Brian Shine ${ }^{1}$, Lawrence Impey ${ }^{1}$, and Manu \\ Vatish $^{2}$ \\ ${ }^{1}$ Oxford University Hospitals NHS Foundation Trust \\ ${ }^{2}$ University of Oxford
}

September 21, 2020

\begin{abstract}
Objective To define a trimester-specific reference interval for C-reactive protein (CRP) in healthy pregnant women, and to evaluate its accuracy for diagnosing infection. Design Retrospective cross-sectional and diagnostic accuracy study. Setting Tertiary hospital in Oxford, UK. Population Development cohort: 315 pregnant women from the Oxford Pregnancy Biobank with uncomplicated pregnancies, with longitudinal sampling in each trimester. Evaluation cohort: 50 pregnant women with suspected chorioamnionitis. Methods and main outcome measures We calculated a $95 \%$ reference interval for CRP in each trimester and evaluated its diagnostic accuracy for infection compared to that from current guidance ([?]7 mg/L). Results Of the 315 healthy pregnant women in our study, concentrations of CRP were substantially higher than those in most nonpregnant populations. The reference intervals in each trimester were similar, with an upper reference limit of $18 \mathrm{mg} / \mathrm{L}$. CRP increased log-linearly with body mass index in all trimesters $(\mathrm{p}<0.001)$. The sensitivity and specificity of CRP for diagnosing chorioamnionitis were $80 \%$ and $86 \%$, respectively. The overall diagnostic accuracy using the pregnancy-specific reference interval was significantly greater than that of the existing standard $(\mathrm{p}=0.002)$. Conclusions A pregnancy-specific reference interval for CRP should be used to optimise diagnostic accuracy for infection in pregnant women. Chorioamnionitis was used as example of a localised infection with well-defined outcomes, but pregnancy-specific upper reference limits for CRP should be considered in any clinical setting including pregnant women.
\end{abstract}

\section{Tweetable abstract}

Using a pregnancy-specific reference limit for C-reactive protein significantly improves diagnostic accuracy for infection.

\section{Introduction}

It is increasingly clear that maternal deaths from infections are more common than was previously appreciated. ${ }^{1}$ The burden of obstetric and non-obstetric infections, which is particularly profound in lowand middle-income countries, ${ }^{2}$ has been addressed in international efforts to prevent maternal mortality, ${ }^{3}$ but sepsis remains the third commonest cause of maternal death worldwide. ${ }^{2}$ The availability of accurate and affordable diagnostic tools is an important prerequisite for diagnosing infection in modern clinical practice, 
but they can be prohibitively expensive, and have rarely been validated in pregnant populations. ${ }^{4,5}$ This prompts us to re-evaluate existing tests, and to consider if we can optimise them for clinical practice.

C-reactive protein (CRP) is an acute phase reactant that rises in response to inflammation, and it is most commonly used to investigate suspected infection. Concentrations of CRP are low in most healthy individuals ${ }^{6}$ but the upper reference limits have been variably reported between 3 and $10 \mathrm{mg} / \mathrm{L} .{ }^{7}$ Pregnancy is associated with immune cell activation and proliferation, ${ }^{8}$ and it has been reported that CRP is elevated in pregnant women from early in the first trimester, ${ }^{9}$ although the extent of this is unclear. Despite this, current guidelines on suspected sepsis by the Royal College of Obstetricians and Gynaecologists recommend using an upper reference limit of $7 \mathrm{mg} / \mathrm{L},{ }^{10}$ which is similar to most non-pregnant standards.

The existing reference intervals (RIs) for CRP are usually derived from non-pregnant populations and often include individuals who are significantly older than most healthy pregnant women. By making comparisons to RIs from an unrepresentative population, the diagnostic accuracy of the test may be compromised. Importantly, pregnancy is a dynamic physiological state associated with progressive, marked plasma expansion and altered hepatic and renal function, ${ }^{11}$ so it cannot be assumed that concentrations of CRP are stable throughout pregnancy. Establishing robust, population-specific RIs is essential for using diagnostic biomarkers safely in clinical practice but, unlike other tests, ${ }^{12}$ there is no established RI for CRP in pregnant women. To address this, we undertook a cross-sectional study of 315 healthy pregnant women to estimate an RI for CRP in uncomplicated pregnancy and evaluated its diagnostic accuracy for chorioamnionitis, as an example of an infection.

\section{Methods}

\section{Development cohort}

We identified potentially eligible participants from the Oxford Pregnancy Biobank between April 2009 and April 2010 and examined them against our inclusion criteria to obtain an objectively healthy population of pregnant women from which to estimate RIs. The Oxford Pregnancy Biobank was a prospective study of pregnant women in Oxford, UK (REC 07/H0607/74), in which pregnancy-specific data were recorded in each trimester and after delivery. A maternal blood sample was taken and stored from the first, second and third trimesters at $10-14^{+6}, 18-23^{+6}$, and $31-38^{+6}$ weeks, respectively.

The inclusion criteria for our study were adult pregnant women ([?]18 years old) with uncomplicated pregnancies. We excluded women with chronic hypertension or diabetes mellitus, and women whose index pregnancy was complicated by gestational hypertension (blood pressure [?]140/90), pre-eclampsia (hypertension with proteinuria), HELLP syndrome (haemolysis, elevated liver enzymes, low platelets), acute fatty liver of pregnancy, gestational diabetes (abnormal oral glucose tolerance test) or obstetric cholestasis (pruritis with bile acids $>14 \mu \mathrm{mol} / \mathrm{L})$.

\section{Analysis}

Plasma CRP was measured using an immunoturbimetric method on the Abbott Architect C16000 analyser (Abbott Laboratories Ltd, Maidenhead, UK) after a single freeze-thaw cycle $\left(-80^{\circ} \mathrm{C}\right)$. Inter-assay imprecision expressed as CV, \% was $5.4 \%$ at $1.6 \mathrm{mg} / \mathrm{L}$, and $1.0 \%$ at $53.6 \mathrm{mg} / \mathrm{L}$, imprecision was $1.02 \%$. The lower detection limit was $0.2 \mathrm{mg} / \mathrm{L}$. 


\section{Statistics}

Data on $\mathrm{CRP}$ in each trimester were approximated to a normal distribution using the natural logarithmic transformation:

$$
f(x)=\ln (x-k)
$$

where $k$ was calculated to minimise skewness. Outliers were identified using Horn's ${ }^{13}$ interpretation of the method described by Hoaglin, et al. ${ }^{14}$ Data were binned into groups of maternal age and BMI, and participants were excluded in whom $\mathrm{CRP}$ was more extreme than 1.5 times the interquartile range above or below the $3^{\text {rd }}$ or $1^{\text {st }}$ quartiles, respectively. The transformations were reapplied after excluding outliers and Shapiro-Wilk tests were used to confirm the distributions.

RIs were calculated for each trimester, equating to the $2.5^{\text {th }}$ and $97.5^{\text {th }}$ percentiles derived from the mean and standard deviation, and the reference limits were presented with their respective $90 \%$ confidence intervals. ${ }^{15}$ One-way ANOVA or Student's t-tests were used to investigate differences in CRP according to groups of maternal age, BMI, mean arterial pressure (at booking), ethnicity, and fetal sex. Participants with missing data in any variable were excluded from subgroup analyses as the frequency of missing data was minimal. ${ }^{16}$ We ran a multivariate linear regression model to investigate the association between CRP and BMI, and investigated partitioning the RIs using the method described by Lahti, et al . ${ }^{17}$ Summary statistics for normally distributed data are presented as the mean and standard deviation, or otherwise as frequencies and proportions. Statistical significance was assumed at the $5 \%$ level, or at the $1 \%$ level for subgroup analyses.

\section{Evaluation cohort}

We evaluated the diagnostic accuracy of the new upper reference limit for CRP for detecting infection, using chorioamnionitis as a well-defined example of infection. We retrospectively identified a subset of 50 consecutive women who had undergone amniocentesis for suspected infection, and extracted the maternal serum CRP to calculate the sensitivities, specificities, positive and negative predictive values, and areas under the receiving operator curves for infection using two reference limits:

- CRP [?]7 mg/L (derived from current guidance on suspected sepsis in pregnancy) ${ }^{10}$;

- The gestation-specific reference limit estimated from the development cohort.

The overall diagnostic accuracy of the two reference standards was compared using receiving operator curve (ROC) analysis. Chorioamnionitis was defined as microbiological growth or microscopic evidence of organisms in amniotic fluid, growth on a placental swab, and/or a histological chorioamnionitis/funisitis if delivery occurred within one week. Women with uterine contractions or evidence of another infection were excluded. Where possible, CRP results were extracted from the same day as the amniocentesis, or within 24 hours.

\section{Results}

\section{Participant characteristics}

A total of 334 women were potentially eligible, of whom $19(5.7 \%)$ were excluded as outliers; details on outliers are presented in Appendix S1. Of the 315 women included in the development cohort, most were white (93\%), had a normal BMI or were moderately overweight, and delivered at full term (mean gestation 40.4 weeks). Most babies did not require admission to the neonatal unit (98.1\%). On average, overweight women ([?]25 kg/m²) had a significantly higher mean arterial blood pressure and gave birth to heavier babies than women with a normal BMI $\left(<25 \mathrm{~kg} / \mathrm{m}^{2}\right)$. Fewer than $2 \%$ of data were missing according to any characteristic. Data on participant characteristics are summarised in Table 1. 


\section{Reference interval development}

Trimester-specific reference intervals for CRP are presented in Table 2.

CRP was not associated with maternal age, mean arterial pressure or ethnicity, but BMI was significantly log-linearly associated with CRP in all trimesters (see Figure 1 and Appendix S2). CRP was marginally higher in women pregnant with male babies than female babies, but this finding was only significant in the second trimester. The statistical conditions for partitioning the reference intervals for CRP by BMI were either met or were marginal in all trimesters, using a cut-off of $25 \mathrm{~kg} / \mathrm{m}^{2}$, so an overall reference interval was used. BMI-specific reference intervals are presented in Table 3 and Figure 2.

\section{Diagnostic accuracy}

The characteristics of women in the development and evaluation cohorts were similar (see Table 1). Of the 50 women in the evaluation cohort, $15(30 \%)$ had chorioamnionitis and $35(70 \%)$ did not have any infection. The median CRP values among women with and without infection were $30.0 \mathrm{mg} / \mathrm{L}$ and $8.1 \mathrm{mg} / \mathrm{L}$, respectively (Mann-Whitney test $\mathrm{p}_{\mathrm{diff}}<0.001$ ).

The overall diagnostic accuracy of CRP for infection was significantly higher when using a pregnancyspecific upper reference limit of $18 \mathrm{mg} / \mathrm{L}$, compared to $7 \mathrm{mg} / \mathrm{L}(\mathrm{p}=0.002)$ (see Figure 3). The sensitivity and specificity using the pregnancy-specific reference limit were $80 \%$ and $86 \%$, respectively. Summary statistics on diagnostic accuracy for both reference limits are presented in Table 4.

\section{Discussion}

CRP in the healthy pregnant women in our study was substantially higher than in most non-pregnant adults. Using a pregnancy-specific RI improved the overall diagnostic accuracy for infection compared to the existing non-pregnant RI, conferring a particular improvement in excluding infection in healthy women without reducing the sensitivity materially. The RIs for CRP were similar in all trimesters with only a small reduction as pregnancy progressed.

The RIs reported in guidelines and large studies of CRP vary substantially, e.g. [?] $7 \mathrm{mg} / \mathrm{L}$ in the UK, ${ }^{10}$ and [?]10 mg/L in the US and Australia. ${ }^{18,19}$ The unmet need for an established pregnancy-specific RI creates diagnostic uncertainty, which risks clinicians disregarding elevated CRP results, or making unnecessary interventions (e.g. iatrogenic delivery). Our study supports using a relatively high upper reference limit for CRP in pregnancy, as this predicted infection with a much greater degree of accuracy than the existing guidance.

The value of using CRP for diagnosing chorioamnionitis through intact membranes is unclear, but there is a growing body of evidence supporting its use in pregnant women with preterm prolonged rupture of membranes. A 2018 meta-analysis reported pooled sensitivities and specificities of $69 \%$ and $77 \%$, respectively, although the upper reference limits for CRP varied widely $(3-18.7 \mathrm{mg} / \mathrm{L}) .{ }^{20}$ The results of our study are similar to those of a more recent review which reported sensitivities and specificities of $59 \%$ and $83 \%$, respectively, using an upper reference limit of $20 \mathrm{mg} / \mathrm{L} .{ }^{21}$ Studies of other blood biomarkers have reported better diagnostic accuracy when using pregnancy-specific reference intervals: Girling, et al. reported that aspartate transaminase, alanine transaminase, bilirubin and gamma glutamyl transferase were lower in pregnancy, and that using these pregnancy-specific RIs significantly improved disease detect rates. ${ }^{22}$

Adipose tissue is known to mount an immune response to overnutrition, ${ }^{23}$ which is likely to drive the elevated levels of CRP seen in the overweight women in this study, as CRP is not able to discriminate between infection and other causes of inflammation. The relationship between obesity and CRP is well documented in pregnant ${ }^{24,25}$ and non-pregnant populations, ${ }^{26}$ but partitioned RIs for CRP are not routinely used in clinical practice. We propose that stratifying CRP results according to BMI would be challenging for routine 
use, but we have presented them for consideration. CRP in women pregnant with male babies was slightly higher than those with female babies, which was statistically significant at the $1 \%$ level in the second trimester only; we include this as it may be useful for consideration in future research.

\section{Strengths and weaknesses}

Ours is the largest study identified to have investigated CRP in pregnant women, and its associations with BMI and gestational age. Our study may include some women with undiagnosed gestational diabetes, as screening is not universal in the UK, but it is uncertain whether this is independently associated with CRP after adjustment for BMI. ${ }^{27}$ Most women in our study were white so we cannot comment on differences in CRP between ethnic groups.

Diagnostic accuracy studies in pregnancy are challenging without a gold standard for maternal infection. Our approach is consistent with previous studies on histological chorioamnionitis ${ }^{20}$ and we have augmented this with microbiological and microscopic data. We acknowledge that the timing of some of the CRP samples (postnatal) may over-represent the antenatal CRP at the actual time of amniocentesis (such procedures are not usually performed in those with a very high CRP). However, within the limits of this pragmatic retrospective study, it should not preclude comparing the two reference limits evaluated here.

\section{Conclusions}

Concentrations of CRP are sufficiently elevated in pregnant women that pregnancy-specific RIs should be used to improve diagnostic accuracy. We have defined and evaluated a new RI for CRP in healthy pregnant women, with specific considerations for characteristics that may modify its limits.

\section{Disclosure of interests}

The authors declare no conflicts of interest.

\section{Acknowledgements}

We are grateful to Sarah Hutchinson for identifying and managing the blood samples.

\section{Contributions}

Study concept (SD, MV, TJ), data synthesis (JB), data extraction (SD, MV), data analysis (SD, MV, TJ), manuscript preparation (SD, JB, TJ, BS, LI, MV), guarantor (MV).

\section{Ethics}

This study was undertaken within the recommendations of the pre-existing ethics approval for the Oxford Pregnancy Biobank (REC 07/H0607/74).

\section{Funding}

Abbott Laboratories provided reagents and funding for this study, but were not involved in the study design, data interpretation or writing of this manuscript. 


\section{References}

1. Bonet M, Brizuela V, Abalos E, Cuesta C, Baguiya A, Chamillard M, et al. Frequency and management of maternal infection in health facilities in 52 countries (GLOSS): a 1-week inception cohort study. The Lancet Global Health. 2020;8(5):e661-e71.

2. Say L, Chou D, Gemmill A, Tunçalp Ö, Moller AB, Daniels J, et al. Global causes of maternal death: a WHO systematic analysis. Lancet Glob Health. 2014;2(6):e323-33.

3. Global, regional, and national levels of maternal mortality, 1990-2015: a systematic analysis for the Global Burden of Disease Study 2015. Lancet. 2016;388(10053):1775-812.

4. Simon L, Gauvin F, Amre DK, Saint-Louis P, Lacroix J. Serum Procalcitonin and C-Reactive Protein Levels as Markers of Bacterial Infection: A Systematic Review and Meta-analysis. Clinical Infectious Diseases. 2004;39(2):206-17.

5. Velazquez-Salinas L, Verdugo-Rodriguez A, Rodriguez LL, Borca MV. The Role of Interleukin 6 During Viral Infections. Frontiers in Microbiology. 2019;10(1057).

6. Abbott. Protein. Learning guide series. 2017. [Available from: https://www.corelaboratory.abbott/sal/learningGuide/ADD-00061642_Protein_Learning_Guide.pdf.

7. Roberts B. Association for Clinical Biochemistry. C-reactive protein (serum, plasma). 2012 [Available from: http://www.acb.org.uk/Nat\%20Lab\%20Med\%20Hbk/CRP.pdf.

8. Mor G, Cardenas I, Abrahams V, Guller S. Inflammation and pregnancy: the role of the immune system at the implantation site. Ann N Y Acad Sci. 2011;1221(1):80-7.

9. Sacks GP, Seyani L, Lavery S, Trew G. Maternal C-reactive protein levels are raised at 4 weeks gestation. Hum Reprod. 2004;19(4):1025-30.

10. Royal College of Obstetricians and Gynaecologists. Bacterial Sepsis in Pregnancy. Green-top Guideline No. 64a. 2012.

11. Soma-Pillay P, Nelson-Piercy C, Tolppanen H, Mebazaa A. Physiological changes in pregnancy. Cardiovasc J Afr. 2016;27(2):89-94.

12. Stricker R, Echenard M, Eberhart R, Chevailler M-C, Perez V, Quinn FA, et al. Evaluation of maternal thyroid function during pregnancy: the importance of using gestational age-specific reference intervals. 2007;157(4):509.

13. Horn PS, Feng L, Li Y, Pesce AJ. Effect of Outliers and Nonhealthy Individuals on Reference Interval Estimation. Clinical Chemistry. 2001;47(12):2137-45.

14. Hoaglin DC, Iglewicz B, Tukey JW. Performance of Some Resistant Rules for Outlier Labeling. Journal of the American Statistical Association. 1986;81(396):991-9.

15. Solberg HE. Approved recommendation (1987) on the theory of reference values. Part 5. Statistical treatment of collected reference values. Determination of reference limits. Clinica Chimica Acta. 1987;170(2):S13-S32.

16. Bennett DA. How can I deal with missing data in my study? Aust N Z J Public Health. 2001;25(5):464-9.

17. Lahti A, Hyltoft Petersen P, Boyd JC, Fraser CG, Jorgensen N. Objective criteria for partitioning Gaussian-distributed reference values into subgroups. Clin Chem. 2002;48(2):338-52.

18. Dhingra R, Gona P, Nam B-H, D'Agostino RB, Sr., Wilson PWF, Benjamin EJ, et al. C-reactive protein, inflammatory conditions, and cardiovascular disease risk. The American journal of medicine. 2007;120(12):1054-62. 
19. Australian Bureau of Statistics. Australian Health Survey. C-reactive protein. [Available from: https://www.abs.gov.au/.

20. Catano Sabogal CP, Fonseca J, Garcia-Perdomo HA. Validation of diagnostic tests for histologic chorioamnionitis: Systematic review and meta-analysis. European Journal of Obstetrics \& Gynecology and Reproductive Biology. 2018;228:13-26.

21. Etyang AK, Omuse G, Mukaindo AM, Temmerman M. Maternal inflammatory markers for chorioamnionitis in preterm prelabour rupture of membranes: a systematic review and meta-analysis of diagnostic test accuracy studies. Syst Rev. 2020;9(1):141.

22. Girling JC, Dow E, Smith JH. Liver function tests in pre-eclampsia: importance of comparison with a reference range derived for normal pregnancy. Br J Obstet Gynaecol. 1997;104(2):246-50.

23. Reilly SM, Saltiel AR. Adapting to obesity with adipose tissue inflammation. Nature Reviews Endocrinology. 2017;13(11):633-43.

24. Shin D, Hur J, Cho EH, Chung HK, Shivappa N, Wirth MD, et al. Pre-Pregnancy Body Mass Index Is Associated with Dietary Inflammatory Index and C-Reactive Protein Concentrations during Pregnancy. Nutrients. 2017;9(4).

25. Holingue C, Owusu JT, Feder KA, Spira AP. Sleep duration and C-reactive protein: Associations among pregnant and non-pregnant women. J Reprod Immunol. 2018;128:9-15.

26. Mehta S, Farmer JA. Obesity and inflammation: A new look at an old problem. Current Atherosclerosis Reports. 2007;9(2):134-8.

27. Retnakaran R, Hanley AJ, Raif N, Connelly PW, Sermer M, Zinman B. C-reactive protein and gestational diabetes: the central role of maternal obesity. J Clin Endocrinol Metab. 2003;88(8):3507-12.

\section{Table 1: Participant characteristics.}

\begin{tabular}{|c|c|c|c|c|c|}
\hline Variable & All women & $\begin{array}{l}\text { Body mass } \\
\text { index }\end{array}$ & $\begin{array}{l}\text { Body mass } \\
\text { index }\end{array}$ & $\begin{array}{l}\text { Body mass } \\
\text { index }\end{array}$ & Missing $(\mathrm{n}, \%)$ \\
\hline & & $<25 \mathrm{~kg} / \mathrm{m}^{2}$ & {$[?] 25 \mathrm{~kg} / \mathrm{m}^{2}$} & $\mathbf{P}_{\text {diff }^{a}}$ & \\
\hline \multicolumn{6}{|l|}{$\begin{array}{l}\text { Development } \\
\text { cohort }\end{array}$} \\
\hline $\mathrm{n}$ & 315 & $182(57.8 \%)$ & $133(42.2 \%)$ & - & - \\
\hline Age, years & $30.5(5.1)$ & $30.3(5.1)$ & $30.8(5.1)$ & 0.41 & - \\
\hline $\begin{array}{l}\text { Body mass } \\
\text { index }\left(\mathrm{kg} / \mathrm{m}^{2}\right)\end{array}$ & $25.1(4.3)$ & $22.2(1.6)$ & $29.2(3.5)$ & - & - \\
\hline $\begin{array}{l}\text { Mean arterial } \\
\text { pressure } \\
(\mathrm{mmHg})\end{array}$ & $79.3(7.9)$ & $77.1(7.5)$ & $82.1(7.4)$ & $<0.0001$ & $5(1.6 \%)$ \\
\hline $\begin{array}{l}\text { White } \\
\text { ethnicity (n, } \\
\% \text { ) }\end{array}$ & $293(93.0 \%)$ & $166(91.2 \%)$ & $127(95.5 \%)$ & 0.15 & $4(1.3 \%)$ \\
\hline $\begin{array}{l}\text { Gestation at } \\
\text { delivery } \\
\text { (weeks) }\end{array}$ & $40.4(1.2)$ & $40.3(1.2)$ & $40.5(1.1)$ & 0.24 & - \\
\hline $\begin{array}{l}\text { Neonatal } \\
\text { birthweight } \\
\text { (kg) }\end{array}$ & $3.5(0.5)$ & $3.4(0.5)$ & $3.6(0.5)$ & $<0.001$ & - \\
\hline
\end{tabular}




\begin{tabular}{|c|c|c|c|c|c|}
\hline Variable & All women & $\begin{array}{l}\text { Body mass } \\
\text { index }\end{array}$ & $\begin{array}{l}\text { Body mass } \\
\text { index }\end{array}$ & $\begin{array}{l}\text { Body mass } \\
\text { index }\end{array}$ & Missing (n, \%) \\
\hline $\begin{array}{l}\text { Neonatal } \\
\text { admission (n, } \\
\%)\end{array}$ & $6(1.9 \%)$ & $5(2.8 \%)$ & $1(0.8 \%)$ & 0.91 & - \\
\hline $\begin{array}{l}\text { Fetal sex, male } \\
(\mathrm{n}, \%)\end{array}$ & $164(52.1 \%)$ & $96(52.8 \%)$ & $68(51.1 \%)$ & 0.84 & - \\
\hline \multicolumn{6}{|l|}{$\begin{array}{l}\text { Evaluation } \\
\text { cohort }\end{array}$} \\
\hline $\mathrm{n}$ & 50 & & & & \\
\hline Cases (n, \%) & $15(30 \%)$ & & & & \\
\hline Age, years & $32.0(5.2)$ & & & & \\
\hline $\begin{array}{l}\text { Body mass } \\
\text { index }\left(\mathrm{kg} / \mathrm{m}^{2}\right)\end{array}$ & $27.2(5.6)$ & & & & \\
\hline $\begin{array}{l}\text { Gestation at } \\
\text { amniocentesis } \\
\text { (weeks) }\end{array}$ & $22.9(3.4)$ & & & & \\
\hline
\end{tabular}

Values shown are means with standard deviations, or frequencies with proportions. Data on age, body mass index and mean arterial pressure were taken at recruitment.

aStudent's t-test or $\mathrm{Chi}^{2}$ between groups.

\section{Table 2: Reference intervals for CRP.}

\begin{tabular}{llll}
\hline & $\begin{array}{l}\text { Calculated reference } \\
\text { interval }(\mathbf{m g} / \mathbf{L})\end{array}$ & $\begin{array}{l}\text { Calculated reference } \\
\text { interval }(\mathbf{m g} / \mathbf{L})\end{array}$ & $\begin{array}{l}\text { Suggested reference } \\
\text { interval }(\mathbf{m g} / \mathbf{L})\end{array}$ \\
\hline Trimester & Upper limit $(\mathbf{9 0 \%} \mathbf{C I})$ & Lower limit $(\mathbf{9 0 \%} \mathbf{C I})$ & \\
First & $21.48(18.64-24.74)$ & $0.46(0.38-0.57)$ & $<18$ \\
Second & $20.46(17.91-23.38)$ & $0.73(0.63-0.84)$ & \\
Third & $18.90(16.45-21.73)$ & $0.75(0.67-0.83)$ & \\
\hline
\end{tabular}

\section{Table 3: Partitioned reference intervals for CRP by body mass index}

\begin{tabular}{|c|c|c|c|c|c|c|c|c|c|}
\hline Trimester & $\begin{array}{l}\text { Body } \\
\text { mass } \\
\text { index } \\
\left(\mathrm{kg} / \mathrm{m}^{2}\right)\end{array}$ & $\begin{array}{l}\text { Reference } \\
\text { interval } \\
(\mathrm{mg} / \mathrm{L})\end{array}$ & $\begin{array}{l}\text { Reference } \\
\text { interval } \\
(\mathrm{mg} / \mathrm{L})\end{array}$ & $\mathbf{R}$ & $\mathbf{D}_{\mathbf{U}}$ & $\mathbf{D}_{\mathbf{L}}$ & \multicolumn{3}{|c|}{ JustificationJustificationJ } \\
\hline & & $\begin{array}{l}\text { Upper } \\
\text { limit } \\
(90 \% \text { CI })\end{array}$ & $\begin{array}{l}\text { Lower } \\
\text { limit } \\
(90 \% \text { CI })\end{array}$ & & & & $\begin{array}{l}\mathbf{R} \\
\text { criteria }\end{array}$ & $\begin{array}{l}\mathrm{D}_{\mathrm{U}} \\
\text { criteria }\end{array}$ & $\begin{array}{l}\mathrm{D} \\
\mathrm{cr}\end{array}$ \\
\hline First & $<25$ & $\begin{array}{l}14.73 \\
(12.32- \\
17.61)\end{array}$ & $\begin{array}{l}0.33 \\
(0.25-0.44)\end{array}$ & 1.09 & 0.73 & 1.07 & Not met & Marginal & \\
\hline
\end{tabular}




\begin{tabular}{|c|c|c|c|c|c|c|c|c|c|}
\hline Trimester & $\begin{array}{l}\text { Body } \\
\text { mass } \\
\text { index } \\
\left(\mathrm{kg} / \mathrm{m}^{2}\right) \\
\end{array}$ & $\begin{array}{l}\text { Reference } \\
\text { interval } \\
(\mathrm{mg} / \mathrm{L})\end{array}$ & $\begin{array}{l}\text { Reference } \\
\text { interval } \\
(\mathrm{mg} / \mathrm{L})\end{array}$ & $\mathbf{R}$ & $\mathbf{D}_{\mathbf{U}}$ & $D_{L}$ & $\begin{array}{l}\text { Justificati } \\
\text { for parti- } \\
\text { tioning }\end{array}$ & $\begin{array}{l}\text { nJustificatior } \\
\text { for parti- } \\
\text { tioning }\end{array}$ & $\begin{array}{l}\mathrm{nJ} \\
\text { fo } \\
\mathrm{ti}\end{array}$ \\
\hline & {$[?] 25$} & $\begin{array}{l}26.01 \\
(21.48- \\
31.49)\end{array}$ & $\begin{array}{l}1.04 \\
(0.82-1.30)\end{array}$ & & & & & & \\
\hline \multirow[t]{2}{*}{ Second } & $<25$ & $\begin{array}{l}13.41 \\
(11.43- \\
15.74)\end{array}$ & $\begin{array}{l}0.63 \\
(0.53-0.75)\end{array}$ & 0.98 & 0.91 & 0.81 & Not met & Met & $\mathrm{M}$ \\
\hline & {$[?] 25$} & $\begin{array}{l}27.00 \\
(22.28- \\
32.73)\end{array}$ & $\begin{array}{l}1.20 \\
(0.99-1.47)\end{array}$ & & & & & & \\
\hline \multirow[t]{2}{*}{ Third } & $<25$ & $\begin{array}{l}13.88 \\
(11.66- \\
16.52)\end{array}$ & $\begin{array}{l}0.67 \\
(0.59-0.77)\end{array}$ & 1.01 & 0.65 & 0.63 & Not met & Marginal & \\
\hline & {$[?] 25$} & $\begin{array}{l}24.03 \\
(19.55- \\
29.55)\end{array}$ & $\begin{array}{l}1.02 \\
(0.86-1.21)\end{array}$ & & & & & & \\
\hline
\end{tabular}

$\mathrm{R}$ is the ratio of standard deviations for groups of body mass index. $\mathrm{D}_{\mathrm{U} / \mathrm{L}}$ is the absolute difference in upper or lower reference limits between groups of body mass index, divided by the smaller of the two standard deviations. Partitioning is justified statistically where $\mathrm{R}>1.5$, or $\mathrm{D}_{\mathrm{U} / \mathrm{L}}$ is [?]0.75. Partitioning may be considered where $\mathrm{D}_{\mathrm{U} / \mathrm{L}}$ is $[?] 0.25$ but $<0.75$. A common reference interval for CRP should be used where $\mathrm{D}_{\mathrm{U} / \mathrm{L}}$ is $<0.25 .{ }^{17}$

\section{Table 4: Diagnostic accuracy of CRP for chorioamnionitis}

\begin{tabular}{lllllllll}
\hline $\begin{array}{l}\text { Reference } \\
\text { interval }\end{array}$ & $\mathbf{n}$ & Cases & Sensitivity & Specificity & PPV & NPV & AUC $^{\mathbf{a}}$ & P $_{\text {diff }}{ }^{\mathbf{b}}$ \\
\hline$[?] 7$ & 50 & 15 & $87 \%$ & $46 \%$ & $41 \%$ & $89 \%$ & 0.66 & $\mathbf{0 . 0 0 2}$ \\
$\mathrm{mg} / \mathrm{L}^{\mathrm{c}}$ & & & $80 \%$ & $86 \%$ & $71 \%$ & $91 \%$ & 0.83 & \\
$<18$ & & & & & & & \\
$\mathrm{mg} / \mathrm{L}$ & & & & & & & & \\
\hline
\end{tabular}

Abbreviations: PPV (positive predictive value), NPV (negative predictive value).

${ }^{a}$ Area under the receiving operator curve. ${ }^{b}$ Non-parametric receiving operator curve analysis. ${ }^{c}$ Derived from Royal College of Obstetricians and Gynaecologists guidance on bacterial sepsis in pregnancy. ${ }^{10}$ 
Figure 1: CRP by body mass index (third trimester)

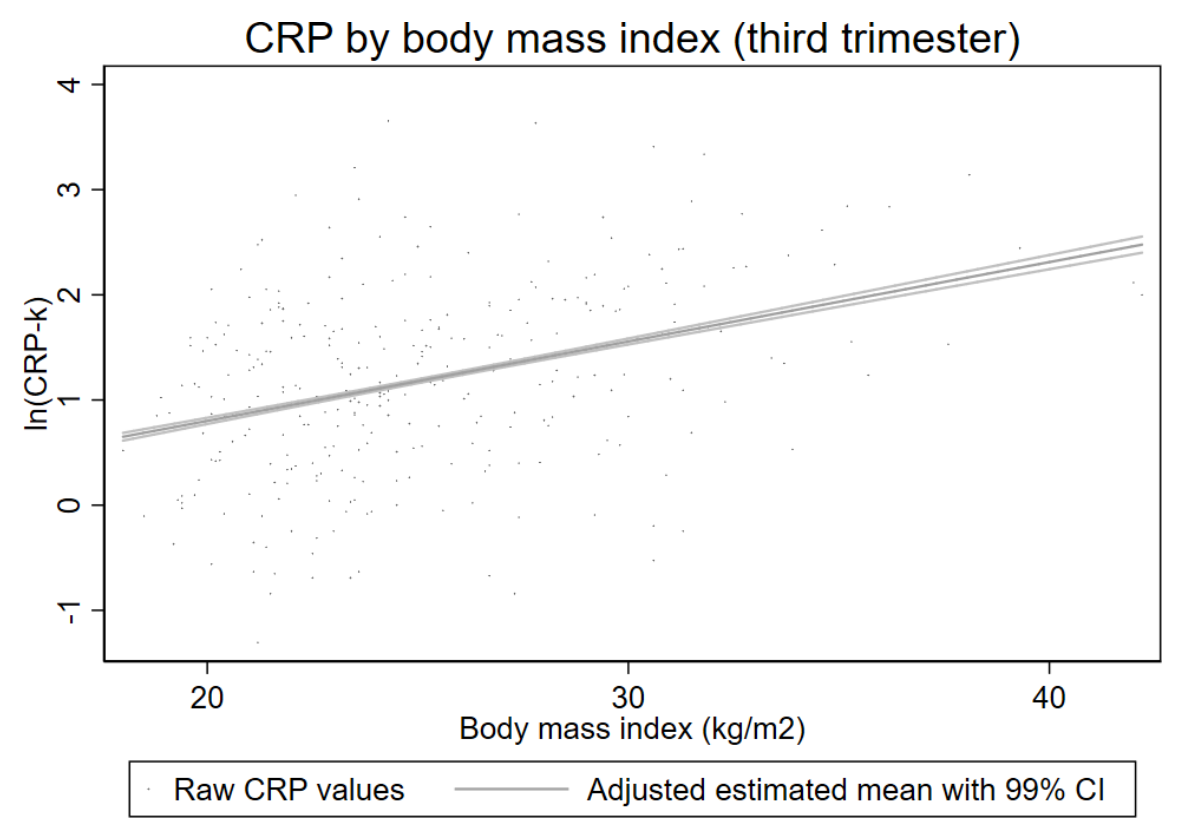

Caption: Adjusted for maternal age, mean arterial pressure and ethnicity.

Figure 2: Upper reference limits for CRP with $90 \%$ confidence intervals

Upper reference limits for CRP with $\mathbf{9 0 \%}$ confidence intervals

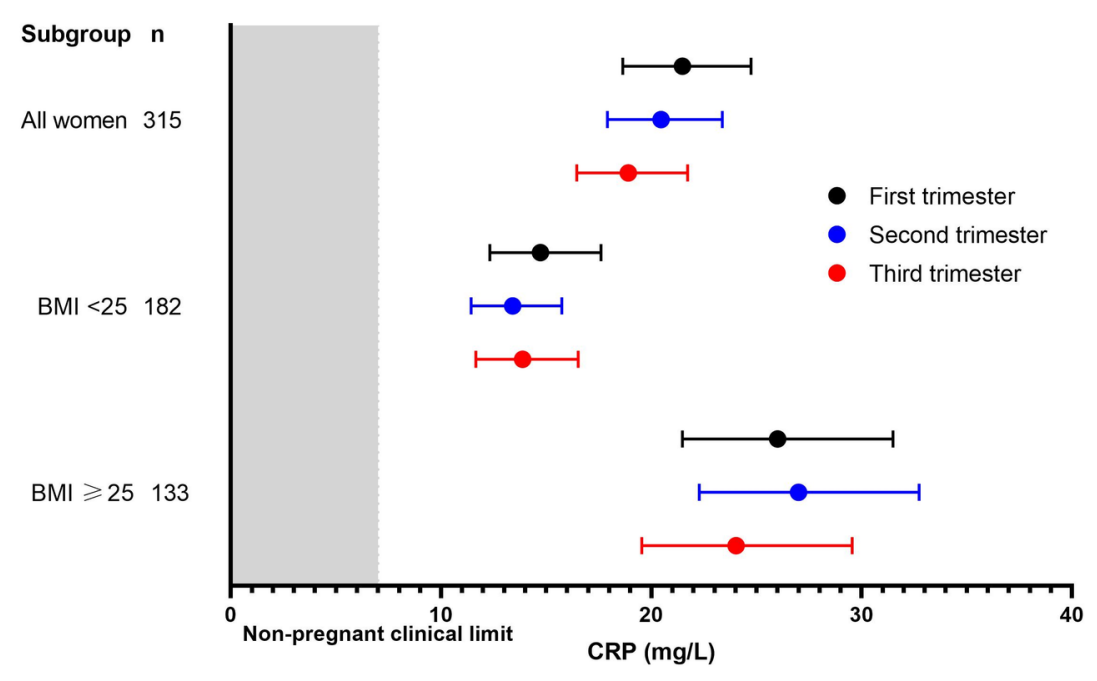


Figure 3: Areas under the receiving operator curves 